\title{
TEACHER ADVOCACY FOR THE ENHANCEMENT OF PROFESSIONAL LEARNING AND DEVELOPMENT IN CONTINUOUS PROFESSIONAL TEACHER DEVELOPMENT PROGRAMMES
}

\author{
N. Dasoo* \\ e-mail: ndasoo@uj.ac.za / https://orcid.org/0000-0002-8671-4340
}

\section{L. van der Merwe Muller*}

PhD Graduate

e-mail: lornavdmm@gmail.com / https://orcid.org/0000-0001-5440-8202

*Department of Education and Curriculum Studies

University of Johannesburg

Johannesburg, South Africa

\section{ABSTRACT}

This article focuses on the key role of teachers in the decision-making process concerning the design and implementation of Continuous Professional Teacher Development (CPTD) at a network of independent schools in Johannesburg. The procedure of examining the role-players in the CPTD process and the level of ownership that teachers appropriate in setting and developing their own topics and goals for training, learning and development are discussed. Activity theory and the theory of communities of practice informed the qualitative study undertaken at three independent primary schools in geographically different areas of Johannesburg. The aim of the study was to indicate that teachers as adult learners can generate useful ideas and topics for CPTD and can inform and improve their practice by recommending effective CPTD activities. Semi-structured interviews, questionnaires and document analysis were employed as data gathering techniques to collect rich data from a purposefully selected sample of primary school teachers. Teachers described activities and methods of learning that could improve their CPTD practices. The findings identify important elements that can be applied in CPTD and professional learning contexts. The proposed elements can be implemented to enhance teacher participation, decision-making and ownership of CPTD and teacher learning.

Keywords: Continuous Professional Teacher Development, training, learning, professional development activities, teacher empowerment, decision-making, ownership

\section{INTRODUCTION}

Continuous Professional Teacher Development (CPTD) is a complex process and ultimately a product in itself. CPTD is the process that should improve a teacher's knowledge of subject content, learning and teaching methods and learning plans (Bertram 2012, 18). It can be defined 
as a continuous process of learning and development over the teacher's career span aimed at improving the teacher's knowledge and skills about how to teach learners more effectively based on various sources either in or external to the school (Schlager and Fusco 2003, 203). We, the authors, argue that CPTD is both the end-product and practice of learning through explicit and implicit methods of development. Explicit methods of CPTD comprise workshops and seminars and more implicit methods include the teacher's reflection on problems and solutions with a colleague down the corridor. Furthermore, we argue that due to the rapid changes in education and schooling systems, teachers should participate in CPTD on a consistent basis in order to avert teaching-career stagnation. Professional development that is effectively designed and implemented may effect positive changes in practice (Harris 2008, 24). Teachers worldwide face educational changes which have a direct effect on their ideas of what education should be (Ochirovna and Moiseyevna 2016, 73). Professional development assists teachers to deal with these changes (King and Feeley 2014, 249). The participants in the study described in this article concurred that CPTD is an apt tool to deal with the changes in society, education and schooling. They felt that technological developments in particular have brought about educational transformation and that CPTD could enable them to grasp and implement the most recent trends in education. The teachers indicated that their CPTD needs are in some way determined by the changing educational environment.

The process of designing CPTD may include the insights of different role-players such as educational departments, service providers, school boards or governing bodies, school managers and leaders, unions and teachers. The different role-players may have different ideas and goals with regard to the most important knowledge and skills that teachers require. Most professional development derives from a "top-down" approach, where supervisors and managers make decisions concerning teachers' CPTD and learning (Macias 2017, 77). Often teachers feel that they are left out of decision-making concerning CPTD. Quaglia and Lande $(2016,33)$ mention that teachers often feel that they are not making decisions for themselves; this exclusion makes them feel disrespected. Hunzicker $(2011,177)$ recommends that teachers' participation must form part of decision-making in their daily practice. King and Feeley (2014, 250) observe that CPTD is often "provided" by other stakeholders, rather than teachers. This provision frequently excludes teachers from making decisions which affects CPTD.

Furthermore, complications in CPTD differentiation arise because of the "one-size-fitsall" approach to CPTD for teachers (Vaughan and McLaughlin 2011, 53). This creates tension, since CPTD usually addresses only generic needs and not individual developmental needs. 


\section{Decision-making, ownership of CPTD and teacher learning: Assisting teachers in creating their orientations for learning and CPTD}

With regard to decision-making and ownership of CPTD, it is vital that not only customary CPTD methods are recognised, but that newer and varied forms of CPTD are given credence as forms of development and learning (Vaughan and McLaughlin 2011, 50). Harris $(2008,22)$ identifies various models for development that include "individualised learnings models, instructor led models, co-learning models and data-based inquiry". In the light of the range of models of CPTD, it is important to discern when to implement each model and how to do this effectively. Macias $(2017,76)$ suggests "bottom-up" models for professional development to be implemented effectively. The bottom-up model uses teachers' decisions and needs as a focus area. Teachers are then able to take ownership of not only how they learn and develop, but also of the areas or topics for development. Moreover, effectiveness of CPTD requires that teachers are part of the decision-making and their input is regarded as part of the process.

On the participation of the teacher in CPTD, Quaglia and Lande $(2016,33)$ identify the importance of including the voice of teachers which they define as the "teachers' ability to speak openly about opinions, ideas, and suggestions in an environment that is driven by trust, collaboration, and responsibility". When teachers' needs are addressed, development and growth ensue (Lee 2005, 41). Teachers should be given opportunities to advocate what they think is important for their CPTD. Teachers are thus enabled to show confidence in their own abilities to find solutions to problems (Torres-Guzmán et al. 2006, 225). When teachers are given a voice in CPTD design, it promises to improve ownership of their own learning. McArdle and Coutts $(2010,209)$ concur that where teachers reflect communally, they improve their learning and practice.

Informal methods and needs assessments create room for teachers to generate ideas and topics for CPTD. Firstly, there should be an atmosphere of "trust", mutual respect and a positive feeling that ideas will not be dismissed, but rather these ideas ought to be discussed by roleplayers in CPTD (Quaglia and Lande 2016,34). Secondly, the problems that arise may be topics for development and should be addressed by a communal forum (Torres-Guzmán et al. 2006). Thirdly, a needs assessment should be conducted to identify topics for CPTD. These will differ from school to school (Hollingsworth 2001, 5). Lastly, opportunities for teacher reflection may guide topics for development (Torres-Guzmán et al. 2006).

Teachers are able adults who can inform their own practices and be self-regulated. To help teachers as adult learners, it is vital to know how adults learn (Snyder 2012,33). Teachers often feel that something as simple as talking to their colleagues and observing colleagues during classroom teaching are effective ways to improve their own practice (Parise, Finkelstein and 
Alterman 2015, 2). When teachers function regularly in a collaborative learning situation, they become more effective teachers (Vaughan and McLaughlin 2011, 54). Teachers who learn and develop in their own educational research and learning communities also improve their participation in CPTD (Torres-Guzmán et al. 2006). Teachers prefer learning and developing in a collaborative format like study groups with their peers (Hollingsworth 2001, 6). Snyder $(2012,49)$ observes that teachers need a culture of "collegiality" for effective CPTD.

\section{Conditions for creating effective CPTD strategies}

When discussing conditions for effective CPTD, it is key to note that ineffective CPTD practice exists. Thus, there is need to ensure that teachers learn and develop adequately and implement that which they have learnt during training in their classrooms. Strategies can be implemented to create more effective CPTD. These strategies and approaches create opportunities for learning and development, but should be implemented on a continual basis. As Brown and Duguid $(1991,41)$ state, "Much conventional learning theory, including that implicit in most training courses, tends to endorse the valuation of abstract knowledge over actual practice and as a result to separate learning from working and, more significantly, learners from workers." Nevertheless, measures can be implemented to eradicate deep-rooted notions of ineffective CPTD. Macias $(2017,86)$ recommends, "Training must be based on teachers' needs, acknowledge learning as a social process, include collaborative opportunities, provide sustainability, treat teachers as active learners, enhance teachers' pedagogical skills and content knowledge, offer facilitation that reflects objectivity and care, focus on learning outcomes for students." In a training and development context, the focus should be on the teacher as a holistic entity, a person with past experiences and future endeavours, as this influences the training process, and thus the outcome of training. Southworth $(1996,272)$ indicates that development and learning should be a regular occurrence in "classrooms and staff rooms". Ochirovna and Moiseyevna $(2016,73)$ make the point that to render any training more successful, the teachers' professional competence and abilities, social development and even their spiritual and emotional well-being should be considered. Lee $(2005,40)$ suggests that CPTD should not be developed separately from other school processes, but should employ different strategies for development. CPTD should be viewed a process and a product within other processes and not be viewed as a separate process within and external to schools.

\section{THEORETICAL FRAMEWORK}

This article draws on Cultural Historical Activity Theory (CHAT) which is used to identify various relationships between the elements of activity theory and to understand tension points 
in terms of the activity (Bourke, Mentis and O'Neill 2013, 36). The CHAT framework can be employed to analyse how individuals and groups of people interact, taking into account historical and cultural aspects (Foot 2014, 330). CHAT signifies various elements within the activity. The "subject" is identified as a person or group being analysed. The "object and outcomes" refer to the context that transfers to an outcome. The "tools" are the conceptual and physical elements that lead to the outcome(s) of an activity (Bourke et al. 2013, 40). The rules and division of labour refer to the rules that oversee the activity by assigning members specific roles in the activity within and overlapping communities against different historical backdrops (Engeström 2001).

\section{Tension identified within the activity of CPTD}

This section discusses how CHAT explains tensions identified in CPTD. The tension identified is that teachers are limited in decision-making in CPTD, and often feel isolated in their CPTD. Primary school teachers (subjects) participate in CPTD through workshops and courses (tools) to update their skills and knowledge and to grow professionally. This is also a regulative requirement of the teaching profession (object) to update skills and knowledge (outcome). The division of labour is between those who plan CPTD (or provide CPTD) for teachers and those who "receive" CPTD. School managers plan CPTD (rules) of the activity. This activity occurs in the context of a school community, overlapping educational communities and larger society. This leads to tension where teachers feel they have limited decision-making about their CPTD because others make the decisions on their behalf.

Furthermore, activity theory can be discussed in terms of five principles (Engeström 2001, 136), namely:

1. The activity system is collective, artefact-mediated and object-oriented;

2. Multi-voicedness of activity systems refers to many and differentiated viewpoints within an activity system;

3. Historicity refers to the problems and solutions in terms of their history;

4. The role of contradictions as sources of changes notes that contradictions exist in the activity and from other activities;

5. The possibility of expansive transformations in activity systems can occur when members start thinking of different methods to do the activity; this leads to a challenge of the status quo.

CHAT as a systematic framework can be employed to analyse data, especially rich and full descriptions of data (Nussbaumer 2012, 37). 
This article, furthermore, explores learning communities as an element of CHAT in CPTD and teacher learning. A special focus on communities of practice as a supplementary framework also guided the analysis. Individual members become part of a community of practice when they take on the value-system of the community, participate in the community and learn from the community (Barab and Duffy 2000, 38). Schlager and Fusco (2003, 205) describe professional development as an activity embedded in communities of practice where participants develop within a community context. Members in community of practice have varied and different levels of "expertise" to contribute to the community; both newer members and those who are established can learn from each other (Schlager and Fusco 2003, 213). This is evident in the varying career-stages of beginner, mid-career and late-career teachers. Schools as sites of CPTD should not only focus on themselves, but also on the communities in which they are embedded (Southworth 1996, 272). Participation in a community is a process that Wenger $(1998,57)$ describes as "a complex process that combines doing, talking, thinking, feeling, and belonging. It involves our whole person, including our bodies, minds, emotions, and social relations."

\section{RESEARCH DESIGN}

The study was qualitative and employed various methods of data collection, such as open-ended questionnaires, interviews and observations. Qualitative research places emphasis on words as a form of data (McCusker and Gunaydin 2015, 537). Notes were recorded during the observations using an observations grid. Participant responses to the interview questions were digitally recorded. Interviews were transcribed and then checked for accuracy. This is an important step given the subjective nature of qualitative research (Hara 1995, 352).

\section{Participants and the sites for data collection}

The research sites comprised three independent primary schools which serve a specific geographical area in urban Johannesburg. Fifteen (15) primary school teachers from the three schools were purposefully selected as participants to produce rich and descriptive data about their perceptions and experiences of CPTD. The sample included beginner, mid-career and latecareer teachers teaching in the Foundation Phase, Intermediate Phase and Senior Phase. Foundation Phase teachers specialise in teaching young learners from Grade 1 to 3; Intermediate Phase teachers teach learners from Grade 4 to 6; and Senior Phase teachers teach learners in Grade 7. Selection criteria required that participants were full-time teachers who had taught for at least one full academic year's experience at the respective school. Participants' experience and teaching qualifications were varied. Qualifications included teaching diplomas, 
education degrees and post-graduate degrees (Honours and Masters degrees). Two participants were completing B Ed Honours degrees part-time at the time of data collection. The responses from participants from all three primary schools presented similar results and are discussed in the findings section.

\section{Instruments}

The instruments for collecting data included questionnaires, semi-structured interviews, observations and document analysis. The questionnaires consisted of open-ended questions to elicit participants' initial ideas, beliefs and opinions about the CPTD in which they had participated and their professional learning. The questionnaires also examined the processes of CPTD as this was an area of interest for the study. Participants completed the questionnaire in their own time and pace. The analysis of responses to questionnaires assisted in the development of interview questions, since this was an opportunity to obtain in-depth information about CPTD. McMillan and Schumacher $(2001,42)$ describes in-depth interviews as a combination of general and more flexible questions. Furthermore, interviews allowed for checking understanding of issues in the questionnaires that required deeper discussion and clarity. All interviews were recorded, transcribed and then checked again against the audio recordings.

Observations were done over several months. Observations included a variety of CPTD sessions, team meetings or training sessions and learning sessions. workshops, group training sessions and small scale training sessions that occurred as once-off sessions and longer-duration sessions. Field notes were kept as record of the observations. Kawulich (2005) states that field notes are an important part of conducting observations. Reflections were competed after each observation and comments made concerning the field notes. School policy documents (from one primary schools in the study) were also a data source. The policy document dealt with teacher training and teacher professional development.

\section{Data analysis}

Qualitative data analysis must start with a strong foundation constructed in collection of data (Bowen 2009, 29). Discourse analysis was employed as method of analysis to develop an understanding of participants' roles and level of participation in the CPTD processes of planning and implementation. Discourse analysis focuses on written, verbal or oral language. Boag-Munroe $(2004,167)$ describes the intersections of activity theory and discourse analysis as follows: "Language is not only at the heart of the activity, as the medium through which the participants communicate, but [it] is also in itself and [in] activity. It has its own rules, which 
allow particular structures [...] to be formed and have meaning; it has a subject who works on the object of expressing concepts, and who is positioned by the other elements of the activity; it uses tools of words, sounds, letters, which in turn afford or constrain ways of working on the object; and language is contextualized in time, place and communities." The language as data sets from the data collection reflected and communicated the experiences of the primary school teachers. It indicated whether they were involved in decision-making of CPTD, and the level at which they were involved. Activity theory as a tool of analysis also focuses attention on various role-players in the process of CPTD and related perspectives of CPTD (Foot 2014, 331). Tensions within the activity of CPTD as a process were illuminated during the analysis phase (Bourke et al. 2013, 35). One tension identified in the activity of CPTD showed that teachers were limited in decision-making in CPTD; for this reason, they often felt isolated in their CPTD. Participants indicated emphatically that they were not involved in decision-making during CPTD. This was a recurring theme in the questionnaires and interviews in the study. Data analysis focused on individual themes and communal themes in terms of communities of practice. CPTD within communities of practice as an effective form of CPTD was identified as a recurring and deep-rooted theme. According to Habhab-Rave (2008), communal learning involving other members are often robust methods of learning and development

\section{Ethical research}

Ethical research is a widely used term that requires that participants are informed about and protected during the study. Participation in this study was voluntary. Participants signed an informed consent form only after the discussion about the purpose and methods of the research had taken place. The principles of confidentiality and anonymity were adhered to throughout the study. Participants' names were not used and they are not identifiable in the study. McMillan and Schumacher $(2001,421)$ mentions that participants and physical settings must not be in any way "identifiable in print".

\section{Validity}

Validity in research refers to accurate measurement of that which was intended to be measured. In other words, research that is sound (Golafshani 2003). Golafshani $(2003,597)$ mentions that validity and reliability must be understood in the context of qualitative research. Validity in the study was increased by asking participants to clarify and explain any unclear issues regarding their reflections of learning and CPTD that emerged during the data collection and analysis phase. 


\section{FINDINGS}

The article argues that teachers can advocate, inform and effectively contribute to their own CPTD. Avalos $(2011,10)$ mentions that the history and traditions of an educational context should be taken into account when evaluating the learning, developmental activities and future training endeavours of teachers. The findings are presented as recommendations that participants devised based on their previous participation in the CPTD.

The value of learning and developing in a community through collaborative sharing of ideas, problems, solutions and life experiences

Teachers in this study wanted to learn and develop in a collaborative manner and environment. Teachers reflected that lecture and seminar type CPTD is a passive type of developmental activity which requires very little from them. They prefer to develop with their peers and share experiences regarding schooling and education in general. In this way, they create a shared meaning. Teachers who reflect together in different communities are able to share views and are also exposed to multiple ideas, rather than a single idea (McArdle and Coutts 2010, 210). A teacher commented on CPTD:

"I think, as for the subject matter and the knowledge, if it is there, then you can learn from everybody and you do learn from everybody every day, which is good."

The above excerpt points to a shared learning that is an effective form of development for teachers. This finding of the value of shared learning and development or collaborative CPTD indicates that communities of learning are an effective forum for teachers to voice questions and share ideas in search of solutions. Teachers found CPTD opportunities to learn from colleagues a helpful and useful practice for development. According to the CHAT model, teachers formed the main subject in the activity (Waters and Wall 2008, 256). Thus, teachers (the subject) indicated that traditional lecture-style CPTD is less preferred as a tool for learning and development.

\section{The need for practical orientation to CPTD}

Participants understood that theoretical knowledge of schooling and education is crucial but requested that CPTD should be more practical and classroom-based in its orientation. Michelsen and Nielsen $(2008,321)$ note that practical knowledge and skills are an important aspect of planning for practice. Macias $(2017,82)$ maintains that teachers have "an appreciation for practical topics". Teachers requested hands-on information and skills that they could apply in the everyday learning context of the classroom. A participant commented: 
"And I think having topics that are relevant to today's classroom and give teachers actual real tools to use. Not just the theory behind it, but the actual implementation of how they can do it, how they can use it with practical examples. Having a speaker come in and drone on the value of an IT classroom, wonderful if we have working WiFi, not a practical implication in our school. So it has to be relevant, it has to be current. So that's where I would look at it."

This finding supports the idea that teachers wanted CPTD to focus on practical and useable aspects of teaching and learning, instead of a predominant focus on theory. It was important for teachers to discover new ideas, skills or knowledge which they could take back to the classroom, with the emphasis on using it every day in lessons. This finding indicates that discussions with CPTD facilitators and trainers should encourage a practical component or a usable aspect in all training and development activities.

\section{CPTD policies should be developed and evaluated with teachers as role- players}

Most participants were unaware if a CPTD policy existed at their schools; those who thought it probably did exist were unsure about its contents. However, the teachers were keen to be part of the process of developing and evaluating a CPTD policy. In this regard, a participant commented:

"Ok, to be honest I've never used one [a CPTD policy] and I've never seen one, but the only thing that I know about it is, at the beginning of the year, [name of school head] told us that we have to do professional development and it will be held [date and time]."

This finding indicates that CPTD should be informed by a well-devised and designed CPTD policy in which teachers are actively involved as role-players and decision- makers. This teacher commented that teachers are "told" when and where CPTD will be held by the school head. Teachers reflected that regular and continual evaluation of CPTD policies should involve them as role-players in CPTD.

Only one school had a written CPTD policy document at the time of data collection and participants from that school were uniformed of its contents. Ball $(1993,11)$ mentions that policy as text is a blend of past actions of social actors, making meaning, knowledge collection within a specific milieu that all come together in creating present policy. CHAT further highlights that an activity system may have many different views and traditions that all contribute to the activity (Engeström 2001, 136). Therefore, policy development should be done in context of other related systems and processes in an organisation such as a school. Ball (1993, 
14) describes policy as not merely a written document but discourse wherein power is constituted in relation to those who can or cannot give input and the content of that input. The finding of this study indicated that teachers did not have authority or power to share in policy discourse or help construct CPTD policy content in their schools.

Furthermore, this finding regarding CPTD policies (and the lack thereof) at the primary schools had additional implications in terms of the annual teacher-appraisal system. Teachers at the schools are evaluated or appraised every year on key criteria such as teaching, learning strategies, extra-curricular activities and professionalism. Under the key performance area of professionalism is teacher professional development whereby teachers are appraised on aspects of their professional development throughout the year, for example, keeping record of all professional development and evidence of professional development. The teacher-appraisal document used by the schools does not refer back to the CPTD policy or practice of the school in any way. This creates a tension in the link between the appraisal system and its criteria and a policy that specifically discusses CPTD. This is evidence of incoherence between the teacherappraisal system (of which CPTD is a key criterion) and the CPTD policy of each school.

\section{The role of team member support}

Teachers reflected that they want to work and learn in dedicated teams or groups of teachers who share similar subjects or grades. Teachers who share mutual rapport are able to create support for each other (Snyder 2012, 49). In the words of a participant:

"I learn best in preparation meetings where things are explained explicitly and simply by subject or grade heads ... It's also like you interact, you go and study, you interact with other teachers, you learn from other teachers, you learn from what they do, which like even though the three schools [names withheld] under the same umbrella, it is so different from our way of how we see the school."

The finding suggests that teachers want to learn in mutual relationships with their peers who teach the same grade or similar subjects. Teachers reflected that their team members, who teach similar subjects and are also committed to a common team ethos, are best able to support each other; each team member has something unique and valuable to share with other team members.

\section{Consultation with teachers regarding CPTD}

Consulting with teachers regarding CPTD is a positive step in creating CPTD that will not only inspire teachers about their learning and development, but also promote their interest in schooling and educational issues. Hunzicker $(2011,177)$ suggests that teachers should be 
consulted in their development; they should have a "... voice in the direction and pace of their learning”. A participant commented:

"Well, what I think it could be useful if perhaps giving us a few options and please say listen we can do A, B or C: What do you think? Can you benefit from or asking us teachers where are the loopholes? Like I think personally I would like to benefit from maybe doing something along counselling the children when they get bullied. Like social work or something like that. To sit with the social worker to say: right, should situation A arrive, do B. Feel like we could need a little bit more help, so perhaps asking us what do we think and maybe as a staff what do you think."

The need for consultation was a striking finding of the study. Teachers want to express their own ideas and dilemmas about learning and development and they wish to be heard in their educational communities and larger society.

\section{The influence of teachers' career-stage on their CPTD needs}

The teachers in the study commented on their specific CPTD needs aligned to their particular career-stage. A novice teacher commented on CPTD: "At this point I am absorbing everything ... at this point". This type of feedback is consistent with Masuda, Ebersole and Barrett (2013, 10) who describe beginner teachers and pre-service teachers as doing "everything and anything" in terms of learning and development.

When asked about professional development as a criterion for teacher appraisal, a novice teacher commented:

"Ok, so I think I'd warm up to the feeling [of being evaluated]. I have never had it before and I think I will have a much better understanding once it's all done in a cycle. I am quite anxious about it. I am not sure how it goes down [how the evaluation process works]."

The teacher described feelings of anxiety regarding the process of teacher appraisal and the role of professional development as one of the main criteria in the teacher appraisal. Masuda et al. $(2013,10)$ make the point that novice teachers often feel "overwhelmed" at the beginning stages of their teaching careers. Effective CPTD can go far in allaying their fears and addressing areas of concern.

Whereas beginner teachers will do almost anything in terms of CPTD due to their awareness of their need to develop as teachers, mid-career teachers are more discriminating in terms of CPTD topics. Mid-career teachers require CPTD based on curriculum content and teaching techniques (Masuda et al. 2013, 10). A mid-career teacher reflected:

"I think it is important to be specific in who you are catering for because we again can miss the 
boat [get professional development wrong]. So if we are having something, for example in the Senior phase, and we include the Junior phase, it is not appropriate for them [professional development appropriate to Senior phase teachers]. So they would have to make sure they [service providers and school managers] are catering either for everybody or then make it specific or even break it up into different groups."

This finding demonstrates that the career stage that teachers find themselves in often has an impact on their development and the kind of professional skilling that they would choose for themselves. Although teachers are in different career-stages, they form part of the community of practice and they are the subjects within the CPTD activity system. As community members they may affect the workings of the CPTD activity (Cameron and Woods 2016, 181). The comment from the mid-career teacher reflects that Senior Phase CPTD is not necessarily appropriate for Junior Phase teachers and that CPTD should implement differentiated learning opportunities. The teacher suggested that the teaching staff should be divided into groups per school phase and curriculum content during CPTD. Mid-career and late-career teachers prefer working with their peers and are more selective and discerning in the professional development they participate in (Masuda et al. 2013, 10).

\section{DISCUSSION}

The subjects in the activity system were the teachers who voiced their perceptions and ideas on improving the CPTD that they had participated in during the past at their respective schools. CHAT focuses on individual elements like the subjects (primary school teachers) and their development and learning objectives as well as the holistic picture of the CPTD activity (Cameron and Woods 2016, 180). Thus, it is vital that teachers should firstly voice their needs, and secondly, they should participate in CPTD that has been designed to meet their needs and to deal with the issues that teachers want addressed with a view becoming better practitioners. A critical component emerging from this study is that teachers are indeed major role-players and decision-makers in their CPTD. The situations they face daily in the classroom, the problems they encounter and the solutions they devise are significant factors that formulate their development. This may differ from school to school and teacher to teacher, but the recommendations may be adapted to local contexts.

When CPTD is developed as a process of teacher inclusion which incorporates ongoing teacher consultation, there is a higher chance of useful learning and development occurring. Teachers who identify their orientations to learning and development can aptly adjust the planning of learning based on the areas they have identified for development. 


\section{CONCLUSION}

The findings from the study are important to consider for current and future research, particularly as related to CPTD policy discussions and formation in schools. Although there is a variety of literature on effective CPTD practices, it is crucial that there is also the continual inclusion of ideas proposed by primary school teachers for CPTD. When teachers are decisionmakers, and their experiences and ideas about CPTD are prized, CPTD learning and development orientations will be fully informed by the principal role-player in CPTD activity - the teachers.

\section{REFERENCES}

Avalos, B. 2011. Teacher professional development in teaching and teacher education over ten years. Teaching and Teacher Education 27: 10-20.

Ball, S. J. 1993. What is policy? Texts, trajectories and toolboxes. Discourse: Studies in The Cultural Politics of Education 13(2): 10-17.

Barab, S. A. and T. M. Duffy. 2000. From practice fields to communities of practice. In Theoretical foundations of learning environments, ed. D. H. Jonassen and S. M. Land. London: Lawrence Erlbaum Associates, Publishers.

Bertram, A. 2012. Getting in touch with your PCK: A look into discovering and revealing science teachers' hidden expert knowledge. Journal of the Australian Science Teacher Association 58(2): $18-25$.

Boag-Munroe, G. 2004. Wrestling with words and meanings: Finding a tool for analysing language in activity theory. Educational Review 56(2): 165-182.

Bourke, R., M. Mentis and J. O’Neill. 2013. Using activity theory to evaluate a professional learning and development initiative in the use of narrative assessment. Cambridge Journal of Education 43(1): 35-50.

Bowen, G. A. 2009. Document analysis as a qualitative research method. Qualitative Research Journal 9(2): $27-40$.

Brown, J. S. and P. Duguid. 1991. Organizational learning and communities of practice: Toward a unified view of working, learning and innovation. Organizational Science 2(1): 40-57.

Cameron, A. and C.Woods. 2016. A proposed "Ladder of learning" for academics' professional development in teaching. South African Journal of Higher Education 30(6): 176-190.

Engeström, Y. 2001. Expansive learning at work: Toward an activity theoretical reconceptualization. Journal of Education and Work 4(1): 133-156.

Foot, K. A. 2014. Cultural-historical activity theory: Exploring a theory to inform practice and research. Journal of Human Behaviour in the Social Environment 24: 329-347.

Golafshani, N. 2003. Understanding reliability and validity in qualitative research. The Qualitative Report 8(4): 597-606.

Habhab-Rave, S. 2008. Workplace learning in communities of practice. In Communities of Practice: Creating learning environments for educators, C. Kimble, ed. P. Hildreth and I. Bourdon, 213231. Charlotte, North Carolina: Information Age Publishing.

Hara, K. 1995. Quantitative and qualitative research approaches in education. The Ontaria Institute for Studies in Education 115(3): 351-355.

Harris, J. 2008. One size doesn't fit all. Customizing educational technology professional development. International Society for Technology in Education. Learning and Leading with Technology 35(7): $22-25$.

Hollingsworth, H. L. 2001. We need to talk. Communication strategies for effective collaboration. 
Teaching Exceptional Children 33(5): 4-8.

Hunzicker, J. 2011. Effective professional development for teachers: A checklist. Professional Development in Education 37(2): 177-179.

Kawulich, B. B. 2005. Participant observation as a data collection method. Forum: Qualitative Social Research 6(2). http://nbn-resolving.de/urn:nbn:de:0114-fqs0502430 (Accessed 12 October 2018).

King, F. and U. Feeley. 2014. Finding the openings amid the closings: One school's approach to taking ownership of teaching and learning. FORUM 56(2): 249-264.

Lee, J-J. 2005. Developing a professional development program model based on teachers' needs. The Professional Educator XXVII(1\&2): 39-49.

Macias, A. 2017. Teacher-led professional development: A proposal for a bottom-up structure approach. International Journal of Teacher Leadership 8: 76-91.

Masuda, A. M., M. M. Ebersole and D. Barrett. 2013. A qualitative inquiry: Teachers' attitudes and willingness to engage in professional development experiences at different career stages. The Delta Kappa Gamma Bulletin International Journal for Professional Educations 79(2): 6-14.

McArdle, K. and N. Coutts. 2010. Taking teachers' continuous professional development (CPD) beyond reflection: Adding shared sense-making and collaborative engagement for professional renewal. Studies in Continuing Education 32(3): 201-215.

McCusker, K. and S. Gunaydin. 2015. Research using qualitative, quantitative or mixed methods and choice based on the research. Perfusion 30(7): 537-542.

McMillan, J. H. and S. Schumacher. 2001. Research in education. A conceptual introduction. $5^{\text {th }}$ Edition. New York: Addison Wesley Longman.

Michelsen, C. and J. A. Nielsen. 2008. Between teaching and researching: Envisaging ownership benefits of involving teachers from an in-service teachers training program in the PARSEL project. Science Education International 19(3): 313-322.

Nussbaumer, D. 2012. An overview of cultural historical activity theory (CHAT) use in classroom research 2000 to 2009. Educational Review 64(1): 37-55.

Ochirovna, K. Z. and S. R. M. Moiseyevna. 2016. Professional formation of the teacher as a source of professional career development. International Journal of Cognitive research in Science, Engineering and Education (IJCRSEE) 4(1): 73-78.

Parise, L. M., C. Finkelstein and E. Alterman. 2015. "We always want to get better": Teachers' voices on professional development. MDRC June 2015.

Quaglia, R. J. and L. L. Lande. 2016. Teacher voice: Problem or potential. Principal. National Association of Elementary School Principals. www.naesp.org (Accessed 15 June 2018).

Schlager, M. S. and J. Fusco. 2003. Teacher professional development, technology, and communities of practice: Are we putting the cart before the horse? The Information Society 19: 203-220.

Snyder, C. 2012. Finding the "royal road" to learning to teach: Listening to novice teacher voices in order to improve effectiveness of teacher education. Teacher Education Quarterly 39(4): 33-53.

Southworth, G. 1996. Improving primary schools: Shifting the emphasis and clarifying focus. School Organisation 16(3): 263-280.

Torres-Guzmán, E., V. Hunt, I. M. Torres, R. Madrigal, I. Flecha, S. Lukas and A. Jaar. 2006. Teacher study Groups: In search of teaching freedom. The New Educator 2(3): 207-226.

Vaughan, M. and J. McLaughlin. 2011. What can motivate teachers to learn? Ask them. Journal of Staff Development, Teacher Voice 32(5): 50-54.

Waters, M. and D. Wall. 2008. Educational CPD: An exploration of the attitudes of UK GP trainers using focus groups and an activity theory framework. Medical Teacher 30(8): 250--259.

Wenger, E. 1998. Communities of practice. Learning, meaning, and identity. Cambridge: Cambridge University Press. 